\title{
A pesquisa em educação ambiental no contexto escolar: contribuições para uma reflexão
}

\author{
Luciano Fernandes Silva* \\ UNIFEI - DFQ e UNESP/ Rio Claro \\ Maria Margarida Gomes** \\ FE - UFRJ e PPG, FE - UFF
}

resumo: Apresentamos as reflexões acerca dos trabalhos do Grupo de Discussão de Pesquisa (GDP) em Educação Ambiental (EA) no Contexto Escolar, desenvolvidos durante o IV EPEA - Encontro de Pesquisa em Educação Ambiental, em 2007. Partindo de uma análise crítica sobre as pesquisas nesse campo, os debates se deram em torno de preocupações e propostas sobre: (i) tensões entre a disciplinaridade dos currículos escolares e a interdisciplinaridade da EA; (ii) temáticas a priorizar na área; (iii) tendências atuais nas pesquisas da área; e (iv) necessidade de diálogos entre o campo da pesquisa em EA e outras áreas de pesquisa no campo da educação. Tais aspectos foram enfocados tanto a partir de considerações de trabalhos sobre disciplinas e conhecimentos escolares como também a partir de produções sobre práticas curriculares interdisciplinares e sobre educação ambiental.

palavras-chave: Educação ambiental, Contexto escolar, Currículo disciplinar, Interdisciplinaridade.

abstract: In this article, we present reflections on the debates occurred in the Research Discussion Group in Environmental Education in schools during the IV EPEA Research Meeting on Environmental Education, in 2007. A critical analysis of the field raised questions and proposals about (i) tensions between integrated curriculum and school subjects, (ii) themes that should receive priority (iii), current research trends, and (iv) the necessity of dialogue between Environmental Education and other areas of educational research. Such points were focused on studies about school subjects, school knowledge, school integrated curriculum and environmental education.

keywords: Environmental education, School education, School subject curriculum, Interdisciplinarity.

\footnotetext{
*Contato:lufesilva@uol.com.br

** Contato: margaridagomes@mls.com.br
} 


\section{Introdução}

A Educação Ambiental (EA) é uma área extensa e complexa formada a partir de interseções com uma ampla diversidade de saberes sociais. Tal constituição apresenta como resultado uma multiplicidade de conceituações que dificultam a construção de consensos. Assim, é possível perceber que são muito diversas as visões de mundo e os objetivos de ação para as problemáticas ambientais dentro da área. Nessa perspectiva, é importante buscar compreender como os diálogos entre os estudos sobre EA e aqueles acerca dos currículos escolares podem ajudar a ampliar e aprofundar os estudos sobre a $E A$ no contexto escolar. A partir dessa idéia geral, apresentamos aqui as reflexões acerca dos trabalhos do Grupo de Discussão de Pesquisa (GDP) em EA no Contexto Escolar, desenvolvidos durante o IV Encontro de Pesquisas em Educação Ambiental, no período de 15 a 18 de julho de 2007.

Representando a diversidade da área, o grupo que participou dos debates era constituído por estudantes de graduação e pós-graduação, professores da escola básica e professores universitários formados numa grande diversidade de áreas específicas, tais como matemática, química, pedagogia, geografia, letras, física e ciências biológicas, observando-se uma leve predominância desta última. Entre os professores atuantes no ensino básico, destacava-se um grupo expressivo que também desenvolvia pesquisas no contexto escolar. Outro aspecto interessante do grupo diz respeito aos cursos de pós-graduação, nos quais parte dos participantes estava inserido, predominando pesquisadores provenientes de Programas de Pós-Graduação em Educação e de Programas de Pós-Graduação em Ensino de Ciências. A experiência pessoal com a pesquisa também foi outro ponto interessante observado na formação do grupo. Este era constituído por pessoas com diferentes níveis de experiência em pesquisa em EA no Contexto Escolar, estando presentes aos debates desde jovens cursando a graduação até mestrandos, mestres, doutorandos e doutores com experiência em pesquisa e docência no nível superior de ensino.

Essa diversidade formativa garantiu um debate forte em termos da multiplicidade de opiniões advindas das mais variadas experiências originárias de espaços e tempos tanto de vivências universitárias como 
escolares. Acreditamos que tal fato caracterizou as discussões do grupo, conduzindo-as para importantes problematizações necessárias aos debates atuais sobre a EA. Assim, os trabalhos se deram inicialmente a partir das concepções, presentes no grupo, sobre as pesquisas relativas à $E A$ no contexto escolar. Essas reflexões se iniciaram com a questão: O que se considera uma boa pesquisa em educação ambiental?

Perguntas como essa mobilizam nossas convicções e nossos conhecimentos sobre a natureza do trabalho científico. Foi inclusive com uma pergunta dessa natureza - O que se considera uma boa pesquisa em educação? - que Marli André iniciou seu texto apresentado no III Seminário de Pesquisa em Educação da UFRGS no ano 2000. Questões como essa são sempre importantes para os pesquisadores do campo educacional. No caso da EA no Brasil $\dagger$, a sua história recente, como área de pesquisa, torna essa questão muito importante. De todo modo, vale ressaltar que a avaliação da produção de pesquisas é coletiva e de longo prazo, envolvendo exposição de idéias e pontos de vista numa ampla discussão entre os interessados.

Assim, a diversidade formativa dos participantes deste GDP, somada aos desdobramentos suscitados pela questão inicialmente colocada ao grupo, acabou por conduzir uma importante discussão. A partir dessa reflexão inicial é que os membros do GDP em $E A$ no contexto escolar foram convidados a apresentar e discutir as pesquisas em EA das quais têm participado, tendo como foco o contexto escolar. Então, a primeira tarefa foi a de analisar as aproximações e os distanciamentos existentes entre as finalidades da educação escolar e aquelas propostas pela EA. Ou seja, este grupo de discussão procurou iniciar reflexões sobre como surgiram e se consolidaram as finalidades educacionais da EA e as da educação escolar, além de buscar identificar as possíveis interseções no

† Novicki (2003), ao analisar as abordagens teóricas e metodológicas das pesquisas brasileiras em Educação Ambiental entre os anos de 1981 e 2002, aponta que a produção discente nacional entre 1981 e 1998 apresenta números que chamam a atenção justamente para o fato de esse ser um campo de conhecimento relativamente novo para a comunidade acadêmica brasileira. Segundo o autor, em 1996 a produção discente nacional em EA representava $0,99 \%$ da produção total dos PPG-EDU (6.935 dissertações/teses) e, em 1998, representava 1,07\% (8.687 dissertações/teses), correspondendo ao crescimento de 34,7\% nessa produção, ocorrido nos anos de 1997 e 1998, de 69 para 93 dissertações/teses. 
plano investigativo entre esses dois campos. Tendo em conta a caracterização dos participantes do grupo, apresentamos a seguir alguns desdobramentos das discussões e reflexões suscitadas durante os trabalhos do GDP em EA no contexto escolar.

\section{Questionamentos e reflexões acerca das pesquisas em EA no contexto escolar}

A especificidade das pesquisas em EA no contexto escolar, desenvolvidas, em desenvolvimento ou simplesmente estudadas pelos integrantes do grupo, suscitou o debate sobre questões como: que pesquisas envolvendo a $E A$ e o contexto escolar têm sido produzidas? Que temas têm sido privilegiados? Que caminhos teórico-metodológicos têm sido escolhidos?

Tais questionamentos resultaram em um debate intenso acerca da percepção de que muitas pesquisas em $E A$ no contexto escolar têm se utilizado de metodologias que partem do princípio da intervenção, como, por exemplo, as pesquisas participativas. Nesse sentido, o grupo de discussão concordou que é preciso muito cuidado com essas abordagens. Isso porque, não raro, encontramos trabalhos que acabam por ficar apenas na intervenção, não podendo ser considerados como produções de pesquisa. Nesse caso, concordamos com André $(1998 ; 1999)$ quando afirma que uma pesquisa científica deve ter preocupações (objetivos) numa perspectiva de longo prazo, possibilidade de certo distanciamento para uma reflexão mais ampla e compromisso com a geração de novos conhecimentos.

Para Alvez-Mazzotti (2001), o desconhecimento das discussões teórico-metodológicas travadas no campo da pesquisa em Educação leva muitos pesquisadores iniciantes a permanecerem excessivamente ligados à sua prática pedagógica, dela derivando seu problema de pesquisa e a ela buscando retornar com aplicações imediatas dos resultados encontrados. Todavia, ressalta a autora, essa crítica não está direcionada para quem decide desenvolver uma pesquisa a partir das dificuldades encontradas na prática pedagógica, mas centra-se justamente no fato de que muitos pesquisadores permanecem apenas no nível de sua prática específica e de 
seus interesses individuais, sem uma tentativa de teorização que permita estender suas reflexões a outras situações.

Como podemos observar, a crítica está direcionada para aqueles trabalhos de intervenção que apresentam como objetivo uma preocupação mais imediata, estando mais relacionados à resolução de problemas cotidianos e, portanto, apresentando um menor distanciamento deles. Trabalhos dessa natureza tendem a colocar a ação como principal objetivo da pesquisa, ou seja, a pesquisa parece sempre estar mais relacionada à resolução de problemas imediatos das práticas pedagógicas das escolas. Perspectivas como essas podem estar relacionadas à concepção de que qualquer pesquisa deve ter uma aplicação prática mais imediata. Isso ilustra bem alguns riscos e desafios que enfrentamos ao propor e realizar pesquisas em EA no contexto escolar, em que os problemas cotidianos exigem, quase sempre, soluções urgentes. Enfim, mesmo considerando a urgência dos problemas escolares e a necessidade de respostas rápidas e eficientes, é preciso lembrar que os conhecimentos produzidos em uma pesquisa científica se caracterizam por um amadurecimento teórico do pesquisador. É importante ter clareza tanto sobre os objetivos de pesquisa quanto sobre os objetivos da prática pedagógica cotidiana.

Os questionamentos colocados inicialmente também levaram o grupo a refletir sobre os enfoques mais presentes nas pesquisas em $E A$ no contexto escolar. Nesse caso, o grupo avaliou que vêm ganhando força as pesquisas diretamente relacionadas com as questões de currículo, que abrangem uma diversidade tanto de perspectivas metodológicas como de temáticas referentes a uma diversidade de contextos escolares. Buscando subsídios para fortalecer esse aspecto do encaminhamento das discussões deste GDP, encontramos apoio em trabalhos do campo do currículo, uma vez que neste a produção de pesquisas sobre a escola tem sido muito marcante.

Ao analisar as relações entre as instâncias macro e micro, em teses e dissertações sobre currículo da educação básica produzidas em programas brasileiros de pós-graduação em educação da região sudeste, no período de 1996 a 2002, Lopes (2006) constata que há uma alta produtividade de investigações sobre objetos bastante diversificados, mas marcadamente associadas a aspectos da prática curricular escolar, tanto do 
currículo escolar geral como também de componentes curriculares específicos. Nesse trabalho, a autora chama a atenção para o fato de que as pesquisas vêm privilegiando empiricamente instâncias micro ou instâncias macroł, muitas vezes não considerando relações entre elas ou apenas estabelecendo relações deterministas:

Como decorrência, questiono também o que entendo como conseqüências dessa análise dicotômica: a perspectiva prescritiva sobre a prática pedagógica nas escolas que deriva, muitas vezes, de não se levar em conta as dinâmicas produtivas do cotidiano escolar, e a perspectiva realista de análise das práticas pedagógicas resultante, em muitas situações, de uma centralidade exclusiva nas dinâmicas microeducacionais ou de um determinismo nas relações macro/micro (LOPES, 2006, p. 630, 631).

Esse estudo apresenta resultados de análises que se mostram muito interessantes para refletirmos sobre as pesquisas em EA, uma vez que para compreendermos esse campo as opções metodológicas devem ser colocadas em pauta. Assim, é importante construir estratégias de pesquisa que levem a compreender a escola como um espaço de construção social de práticas curriculares específicas, mas também entender como essas práticas se relacionam com outras práticas sociais acontecendo fora de seus limites.

Além disso, os trabalhos do GDP em EA no contexto escolar se caracterizaram por um encaminhamento, que consideramos importante, relacionado aos estudos que compreendem a escola como uma instituição caracterizada por dinâmicas produtivas de conhecimento. Em relação a esse tema, Chevallard (1998), Forquin (1992) e Lopes (1997, 1999) apontam, em seus diferentes trabalhos, que os diversos conhecimentos

‡ A autora, baseada no trabalho empírico de cada pesquisa, considera que a instância macro engloba as pesquisas com foco nas disposições legislativas, propostas curriculares oficiais, incluindo a sua história, história das disciplinas no sistema educacional em documentos oficiais e/ou livros didáticos e análise da organização curricular. Já a instância micro abrange as investigações com abordagens metodológicas centradas no cotidiano da escola ou da prática pedagógica, nas concepções dos sujeitos em uma dada instituição escolar ou da instituição escolar como um todo, no uso dos livros didáticos, na história do currículo sobre o cotidiano escolar e nos estudos de caso. 
que chegam à escola se transformam em conhecimentos escolares por meio de múltiplas interpretações feitas pelas suas diversas instâncias, como, por exemplo, os professores, os livros didáticos, os coordenadores e os alunos. Assim, a educação escolar faz um complexo trabalho de transposição didática, tornando os materiais da cultura selecionados acessíveis às gerações mais jovens (FORQUIN, 1992).

Nesse sentido, as contribuições dos estudos sobre cultura escolar e/ou disciplinas escolares relacionados a autores como Jean-Claude Forquin (1992, 1993), André Chervel (1990), Dominique Juliá (2001, 2002) e Ivor Goodson (1983, 1997, 1998, 2001), e, no Brasil, Alice Lopes (1997, 1999), Elizabeth Macedo (1999) e Macedo \& Lopes (2002), podem ser de grande valor para compreendermos os debates do GDP em E $A$ no contexto escolar. Os estudos desses autores, cujas perspectivas nem sempre convergem, nos ajudam a compreender os contextos escolares como espaços socialmente dinâmicos e produtivos.

Dessa forma, as disciplinas escolares podem ser consideradas expressões curriculares de diversas influências históricas, incluindo disputas decisivas na seleção de quais conteúdos, métodos e objetivos são legítimos (GOODSON, 1983). As disciplinas escolares organizam o currículo escolar e são formadas por conhecimentos que passam por diversas transformações, sendo produzidos a partir de conhecimentos acadêmicos, cotidianos e pedagógicos. Esses conhecimentos constituem-se em formas de cultura com características próprias que mostram que a escola não é um lugar passivo que pode ser visto apenas como um receptáculo dos produtos culturais da sociedade (CHERVEL, 1990; JULIÁ, 2001, 2002).

Desse modo, os conhecimentos escolares apresentam-se expressos sob a forma de disciplinas escolares, que estruturam e organizam o currículo escolar, ou seja, podem ser vistas como mecanismos analíticos, de apropriação da realidade cotidiana, que não são neutros e se constituem como formas de poder e controle. Ao longo da história da escolarização, a organização curricular via disciplinas tem sido amplamente aceita, mas tem também suscitado diversas críticas no que diz respeito à sua incapacidade de dar conta das problemáticas sociais. A partir dessas posições, têm surgido propostas alternativas aos mecanismos disciplinares, apresentando-se ora como novos campos de saberes 
interdisciplinares, ora como temáticas integradoras dos diferentes campos de saberes disciplinares. No entanto, em ambos os casos há uma tendência marcante de identificação das disciplinas escolares com aquelas de referência científica (MACEDO; LOPES, 2002, p. 82). Dessa forma,

[...] independente dos discursos de articulação disciplinares, a matriz disciplinar persiste como instrumento de organização e controle do currículo. Ainda que as atividades curriculares possam estar organizadas segundo lógicas diversas das aceitas na constituição de campos científicos, as disciplinas escolares tendem a se manter como "tecnologia" de organização curricular relacionada aos fins sociais do conhecimento e da educação (MACEDO; LOPES, 2002, p. 82).

No caso da EA no contexto brasileiro, principalmente na última década, os debates sobre a forma mais adequada para a sua inserção nos currículos escolares têm oscilado entre propostas para um novo componente curricular e projetos interdisciplinares que envolvam os componentes curriculares tradicionais. Nesse embate entre o disciplinar e a integração, muitos dos pressupostos da EA vêm sendo inseridos nos conteúdos e estratégias de ensino das disciplinas escolares (CARVALHO, 2005 e 2006; SILVA, 2001; SILVA; CARVALHO, 2006a , 2006b). Ou seja, muitos dos princípios da EA têm penetrado nos programas de ensino através da seleção de conteúdos que valorizam aspectos relativos às questões ambientais.

A despeito dos resultados desses debates, o campo da EA pode ser reconhecido atualmente como fazendo parte das múltiplas influências que contribuem para a seleção do que é ensinado nas disciplinas escolares. Por exemplo, Oliveira e Ferreira (2007) §, ao analisarem um levantamento sobre atividades de EA desenvolvidas em escolas do estado do Rio de Janeiro, identificaram diversas escolhas feitas por professores na produção de atividades de ensino que revelam influências tanto dos campos disciplinares de referência como daquele da EA. No entanto, chamam a atenção para o fato de que essas produções apresentam um caráter

\footnotetext{
$\checkmark$ A primeira autora desse trabalho participou das atividades do GDP em EA no contexto escolar.
} 
eminentemente escolar e, portanto, reafirmam o contexto escolar como um espaço de produção de saberes.

Tal influência pode ainda ser percebida nos trabalhos de Gomes (2006, 2007) acerca dos conhecimentos ecológicos escolares veiculados por livros didáticos de Ciências, mostrando que tais conhecimentos se constituem a partir da integração de conhecimentos referenciados no campo científico da ecologia biológica com valores e saberes referentes a movimentos tais como os socioambientais, os educacionais e ainda os do ensino de Ciências. Dessa forma, esses trabalhos indicam que esses conhecimentos não estão integrados aos demais conteúdos de ciências, embora possam ser observadas tentativas para que isso seja possível. Ao contrário, apresentam uma integração com valores referentes principalmente a questões ambientais, como a preservação de biodiversidade, ecossistemas e uma melhoria de vida humana no cotidiano contemporâneo.

Sendo assim, é possível afirmar que o campo da EA se insere nos embates e disputas que fazem parte da seleção de conteúdos, métodos e objetivos das disciplinas do currículo escolar. Isso significa que, na elaboração dos conhecimentos de cada disciplina, a educação ambiental pode se mesclar tanto com as ciências de referência como com outros conhecimentos cotidianos e pedagógicos, formando um corpo de conhecimentos escolares. Nesse processo, travam-se os conflitos e debates acerca da inserção da EA nas instituições escolares.

Enfim, as reflexões do grupo sobre as pesquisas em $E A$ no contexto escolar que focalizam questões relacionadas ao currículo escolar nos possibilitaram discutir e apontar novas propostas investigativas. Tais propostas sugeriram novamente reflexões e discussões, sendo que algumas delas suscitaram tensões de natureza epistemológica que, certamente, não iremos explorar com o devido aprofundamento neste trabalho.

\section{A pesquisa em EA no contexto escolar: algumas reflexões e propostas}

Os debates do GDP em EA no contexto escolar se encaminharam para quatro principais eixos de preocupações e propostas: (i) tensões 
existentes entre o caráter disciplinar dos currículos escolares e as propostas aparentemente consensuais acerca da interdisciplinaridade da EA; (ii) temáticas a priorizar nas pesquisas sobre EA nas práticas curriculares escolares; (iii) tendências preponderantes atuais nas pesquisas em $E A$ no contexto escolar, (iv) necessidade de busca de diálogos entre o campo de pesquisa em EA e outras áreas de pesquisa no campo da educação.

No que diz respeito à existência de tensões entre a organização curricular disciplinar escolar e a possibilidade de sua transformação para uma organização interdisciplinar, concluiu-se que é preciso avançar nesse debate. Além das questões mais diretamente relacionadas aos estudos sobre currículo, disciplinas escolares e conhecimento escolar, faz-se necessário avançar nas investigações sobre as concepções que circulam entre os professores de nível básico de ensino a respeito dos processos de produção de conhecimentos e, mais especificamente, sobre os conhecimentos produzidos tanto nos contextos escolares como nos contextos científicos. Ou seja, é preciso compreender como os professores organizam as suas propostas de ensino em perspectivas tanto disciplinares como interdisciplinares.

Em pesquisa realizada com futuros professores de Física, Silva (2007) aponta para o risco que pode significar o entendimento de que as questões referentes a trabalhos interdisciplinares se encontram esclarecidas. Segundo o autor, que investigou as propostas e práticas de ensino de futuros professores de Física, o significado de trabalhos dessa natureza nem sempre é compreendido de forma clara. Daí o autor ter observado que, para futuros professores de Física, a idéia de interdisciplinaridade está vinculada à possibilidade de um professor de Física discutir assuntos específicos e pertinentes a outros campos do conhecimento, como, por exemplo, o campo da Biologia ou da Geografia. Para os futuros professores de Física, as propostas e práticas de ensino interdisciplinares reforçavam a não-identificação deles com trabalhos educativos que tratavam de aspectos da temática ambiental. Assim, a menção da necessidade de trabalhos interdisciplinares justificava a nãoadesão desses professores em formação com práticas de ensino que tratavam de temas que envolviam a relação entre ser humano e natureza. 
Nesse sentido, é importante retomar o trabalho de Veiga-Neto (2006), que nos alerta para interpretações equivocadas sobre o conceito de interdisciplinaridade no contexto pedagógico. Segundo o autor, freqüentemente surgem novas palavras de ordem e apressadas propostas educacionais, sendo preciso, portanto, retomar algumas questões básicas, mapear e ressignificar velhos conceitos, além de examinar e colocar sob suspeita antigas e cristalizadas verdades.

Do mesmo modo, Rodrigues (2001) nos alerta para o fato de que devemos colocar sob suspeita certas conclusões apressadas que são assumidas como verdades pedagógicas. $\mathrm{O}$ autor indica que algumas palavras comuns no campo da educação freqüentemente não são esclarecidas de forma adequada, falta-lhes fôlego teórico. Nesse sentido, expressões como "trabalhos ou currículos interdisciplinares", não raro, ainda se encontram muito mal interpretadas quanto ao seu significado. Isso porque na verdade apresentam diferentes significados em contextos sociais distintos, como, por exemplo, nos contextos escolares e nos contextos científicos e acadêmicos.

Ainda segundo alguns autores (LOPES, 1999; PIERSON; NEVES, 2000; GALLO, 2001), não há um consenso quanto ao significado do termo interdisciplinaridade. Contudo, freqüentemente, o termo pode traduzir apenas uma mera superposição de disciplinas escolares, sem que, efetivamente, haja um diálogo entre elas nas práticas curriculares. Tal interpretação pode estar relacionada a concepções limitadas sobre a natureza de produção dos conhecimentos, tanto científicas como escolares. Ou seja, concepções aligeiradas de alguns termos podem influenciar as práticas pedagógicas, prevalecendo, no trabalho escolar, perspectivas não muito consistentes acerca da interdisciplinaridade.

Mesmo considerando o caráter eminentemente escolar da produção das propostas de ensino dos futuros professores, Silva (2007) indica que alguns deles procuram justificar suas ações interdisciplinares ora se valendo de idéias mais próximas do âmbito da pedagogia, ora se valendo de idéias mais diretamente relacionadas com uma determinada visão sobre a atividade científica. A consideração dessa falta de clareza em relação ao entendimento da natureza do trabalho interdisciplinar deve servir de alerta para as pesquisas em EA, tendo em conta que "o caráter 
interdisciplinar" é um dos princípios metodológicos mais reconhecidos nos trabalhos definidores dessa área.

Cavalari, Santana e Carvalho (2006), ao analisarem as concepções de educação e de EA nos trabalhos apresentados no I EPEA, destacaram que a interdisciplinaridade tanto é vista como um elemento que caracteriza a teoria e a prática corrente na EA quanto é entendida como fruto de uma concepção de meio ambiente. Ainda segundo os autores, a interdisciplinaridade também é apresentada nos textos de pesquisa em EA como um princípio básico para o planejamento e desenvolvimento de propostas de educação ambiental.

Ao estudar o assunto, Gallo (2001) indica que a interdisciplinaridade na educação foi pensada como uma das possibilidades de reorganizar o trabalho educativo. Nesse sentido, ela deveria possibilitar uma nova apreensão dos saberes, desta feita não mais identificada pela absoluta compartimentalização das disciplinas, mas pela comunicação entre os compartimentos disciplinares.

Para Pierson e Neves (2000), a interdisciplinaridade ganha força na educação a partir da demanda por uma formação mais global do homem, com a conseqüente superação de sua visão fragmentada do mundo.

Leff (2002), a respeito da produção do conhecimento científico, considera que o grande indutor da interdisciplinaridade foi, sem dúvida, o movimento histórico de transformação das bases do processo produtivo. Essa transformação exigiu novas e articuladas aplicações práticas das Ciências que, do ponto de vista epistemológico, induziram a construção de um novo objeto científico com base na colaboração de diversas disciplinas, e não apenas como o tratamento comum de uma temática. Nesse sentido, está-se diante de um novo objeto de estudo e de uma nova forma de interrogá-lo. Ou seja, a interdisciplinaridade é especificada no campo teórico de produção do conhecimento científico e não de suas práticas.

Ainda segundo Gallo (2001), do ponto de vista educativo, a interdisciplinaridade também indica a possibilidade da realização de trabalhos em equipe, nos quais os professores de diferentes disciplinas agregam conhecimentos sobre um determinado tema em comum. 
Partindo desses diferentes apontamentos, consideramos relevante que possam ser produzidos trabalhos que investiguem as diferentes concepções sobre trabalhos interdisciplinares presentes na escola básica. Nesse sentido, Kawamura (1997) critica o entendimento mais comum do termo interdisciplinaridade. A autora observa que é importante reconhecermos o fato de que propostas de trabalhos integrados do ponto de vista pedagógico não devem prescindir daqueles conhecimentos básicos das diferentes disciplinas, ou seja, trabalhos interdisciplinares deveriam apresentar, em geral, referências fortes em produções disciplinares. Nesse sentido, a idéia de disciplinaridade é importante para demarcar e compor as diferentes perspectivas de conhecimento.

Outro aspecto importante a considerar em pesquisas de $E A$ no contexto escolar é que utilizar pressupostos interdisciplinares para avaliar uma instituição que historicamente se organiza a partir de disciplinas pode resultar em análises que desconsideram atividades e produções caracteristicamente escolares. Considerando isso, trabalhos como o de Lima e Vasconcellos $(2007)^{* *}$ revisitam oportunamente a discussão acerca do caráter disciplinar dos currículos escolares em contraponto às propostas interdisciplinares da EA. As autoras desse trabalho apresentam dados sobre escolas do estado do Rio de Janeiro, mostrando exemplos de projetos de ensino de EA com características disciplinares. Tais exemplos revelam produções culturais relacionadas com a forma de organização curricular própria do universo escolar e que devem ser compreendidas "a partir de um referencial que considera a materialidade das relações estabelecidas na escola e desta com seu contexto sócio-históricoeducacional.” (LIMA; VASCONCELLOS, 2007, p. 14). Com base nessa perspectiva, é possível compreender "a criatividade e os saberes mobilizados na construção de ações pedagógicas extremamente ricas" (LIMA; VASCONCELLOS, 2007, p. 14).

Então, partindo do entendimento de que as práticas curriculares escolares são fortemente caracterizadas por sua história disciplinar, o grupo de discussão elegeu como temas principais a priorizar nas pesquisas em $E A$ no contexto escolar aqueles relacionados: (i) à construção do projeto

\footnotetext{
** As autoras desse trabalho participaram do GDP em EA e o contexto escolar.
} 
político-pedagógico da escola, ou seja, a educação ambiental se define a partir de um projeto político-pedagógico (LIMA; VASCONCELOS, 2007); (ii) às tensões entre disciplinaridade e interdisciplinaridade nas práticas curriculares escolares; (iii) à ambientalização dos currículos escolares considerando a integração entre perspectivas macro e micro de análise, quer dizer, priorizando as análises que se detenham nas relações entre as perspectivas como as das propostas oficiais e aquelas das práticas curriculares do cotidiano escolar; (iv) ás concepções diversas de conhecimentos, como, por exemplo, da pedagogia, da física, da química, da biologia, etc.; (v) aos trabalhos escolares que partem de projetos; e (vi) às políticas públicas educacionais.

Esses temas, propostos como prioritários, surgiram das discussões do grupo acerca das tendências preponderantes de pesquisa em EA, campo este que, como já explicitado anteriormente, parece predominantemente estar sendo construído a partir de trabalhos de intervenção. No entanto, o grupo ressaltou que é fundamental a elucidação da idéia de que intervenção por si só não é pesquisa. Só é pesquisa quando produz conhecimento. $\mathrm{O}$ fundamental é que as pesquisas em $\mathrm{E} A$ no contexto escolar priorizem os diálogos com os atores sociais da escola.

Por fim, foram identificadas as interfaces possíveis da pesquisa em EA com outros campos de produção sobre os contextos escolares, tais como a formação de professores, as disciplinas escolares, a cultura escolar, o ensino de Biologia, Física, Química, História, Geografia e o cotidiano escolar. Para exemplificar, podemos dizer que os estudos sobre formação inicial e continuada de professores tratam, entre outros temas de interesse para a área de EA, de identidade e profissionalização docente, de processos de formação em serviço, das questões referentes à prática pedagógica, de propostas de governo ou Secretarias de Educação, de programas ou cursos de formação, além de focalizar aspectos bastante variados, tais como recursos pedagógicos (ANDRÉ, 1999).

Enfim, consideramos importante e vital para a área de EA aprofundar o diálogo entre especialistas de diferentes áreas do conhecimento e com diferentes experiências na pesquisa e na prática profissional. 


\section{Considerações finais}

Tendo em conta a diversidade e a quantidade das pesquisas em EA que vêm sendo produzidas atualmente, entendemos que os fóruns de debates como os do EPEA possibilitam reflexões e discussões essenciais para a compreensão dos conhecimentos produzidos nessa área. A partir da possibilidade de debatermos as finalidades e os significados de nossas pesquisas, a principal proposta deste GDP em EA no Contexto Escolar esteve direcionada para a necessidade de realizarmos discussões mais profundas para a compreensão das pesquisas em EA no contexto escolar.

Alguns aspectos discutidos neste GDP mostraram a necessidade de refletirmos mais acerca dos possíveis "resultados" de nossas pesquisas e das nossas opções metodológicas. Se de um lado é possível defender um caráter mais pragmático para as pesquisas que envolvem as instituições escolares de forma mais direta, de outro é razoável considerar que o tempo da pesquisa é diferente do tempo da ação. Além disso, muitos defendem que o propósito da pesquisa deve ser mais voltado para a produção de conhecimento na área. No entanto, o grupo de discussão também chamou a atenção para o fato de que há diferentes perspectivas e enfoques para as pesquisas em $E A$ no contexto escolar que apresentam procedimentos de intervenção para coleta de dados. Tais procedimentos não se constituem num problema em si, tampouco a forma pela qual as pesquisas são desenvolvidas pode se ater unicamente aos processos de intervenção.

Um outro aspecto enfatizado pelo grupo foi a falta de clareza acerca dos pressupostos da interdisciplinaridade, tanto na pesquisa quanto na prática pedagógica. Partindo da constatação de que existe um consenso aparente em torno das abordagens interdisciplinares no campo da EA, o grupo concluiu sobre a importância de reavaliar os significados desse termo e as suas possibilidades de aplicação em atividades pedagógicas.

Também foi enfatizado pelo grupo que há uma necessidade de diálogo das pesquisas em EA com outros campos de pesquisa, tais como a formação de professores, as disciplinas escolares, o conhecimento escolar, o cotidiano escolar e o ensino das diversas áreas científicas. O grupo entendeu que o campo de pesquisa em EA deve construir um diálogo intenso com outros campos de pesquisa em Educação. $O$ interesse de 
muitos pesquisadores em EA pela formação de professores é um exemplo da possibilidade de construirmos férteis diálogos entre dois campos específicos do conhecimento.

Por fim, uma outra indicação forte do grupo foi a de que os resultados dos trabalhos de pesquisas em $E A$ no contexto escolar devem ser apresentados aos atores sociais das escolas. As instituições escolares não podem ser consideradas apenas espaços a serem analisados e estudados. Ações de retorno das produções dessas pesquisas podem possibilitar uma intensa e fértil troca entre os atores das instituições escolares e de pesquisa.

\section{Referências}

ALVEZ-MAZZOTTI, Alda Judith. Relevância e Aplicabilidade da Pesquisa em Educação. Educação e Sociedade, Campinas, n. 113, p. 39-50, dez. 2001.

ANDRÉ, Marli. Desafios da pesquisa sobre a prática pedagógica. In: ENCONTRO NACIONAL DE DIDÁTICA E PRÁTICA DE ENSINO, 9., 1998, Águas de Lindóia, SP. Anais... Águas de Lindóia: USP, 1998.

Pesquisa em Educação: buscando rigor e qualidade. Educação e Sociedade, Campinas, n. 113, p. 51-64, dez. 1999.

CARVALHO, Luiz Marcelo. A Temática Ambiental e o Ensino de Biologia: compreender, valorizar e defender a vida. In: MARANDINO, Martha et al. (Org.). Ensino de Biologia: conhecimentos e valores em disputa. Niterói: EDuff, p. 85-99, 2005.

. A Temática Ambiental e o Processo Educativo: dimensões e abordagens. In: CINQUETTI, Heloisa Sisla; LOGAREZZI, Amadeu (Org.). Consumo e Resíduos Fundamentos para o trabalho educativo. São Carlos: EdUFSCar, 2006. p.19-41.

CAVALARI, Rosa Maria F.; SANTANA, Luiz Carlos; CARVALHO, Luiz Marcelo. Concepções de educação e educação ambiental nos trabalhos do I EPEA. Pesquisa em Educação Ambiental, São Carlos, v. 1, n. 1, p. 141-173, jul./dez. 2006.

CHERVEL, André. História das disciplinas escolares: Reflexões sobre um campo de pesquisa. Teoria \& Educação, Porto Alegre, n. 2, p. 177-229, 1990.

CHEVAlLARD, Yves. La transposición didáctica - Del Saber Sábio Al Saber Enseñado. Buenos Aires: Aique Grupo Editor S. A., 1998.

FORQUIN, Jean-Claude. Saberes escolares, imperativos didáticos e dinâmicas sociais. Teoria \& Educação, Porto Alegre, n. 5, p. 28-49, 1992.

Escola e Cultura - As bases epistemológicas do conhecimento escolar. Porto Alegre: Artmed, 1993. 
GALLO, Sílvio. Transversalidade e Meio Ambiente. 2001. Disponível em: < http://www.inep.gov.br/download/cibec/pce/2001/15-26.pdf>. Acesso em: 18 jan. 2006. Ciclo de Palestras sobre Meio Ambiente - Programa Conheça a Educação do Cibec/Inep-MEC/SEF/COEA, 2001.

GOMES, Maria Margarida. Conhecimentos ecológicos em livros didáticos de ciências. In: COLÓQUIO SOBRE QUESTÕES CURRICULARES \& III COLÓQUIO LUSOBRASILEIRO, 7., 2006, Braga, Portugal. Livro de Resumos. Braga, Portugal: CIED/Universidade do Minho, 2006.

. Transformações dos conhecimentos ecológicos em livros didáticos de ciências. In: ENCONTRO NACIONAL DE ENSINO DE BIOLOGIA, 2. \& ENCONTRO REGIONAL DE ENSINO DE BIOLOGIA DA REGIONAL 04 (MG/TO/GO/DF), 1., 2007, Uberlândia. Anais... Uberlândia, MG: Associação Brasileira de Ensino de Biologia, 2007. No prelo.

GOODSON, Ivor F. School Subjects and Curriculum Change: Studies in Curriculum History. London: The Falmer Press, 1983. - A Construção Social do Currículo. Lisboa: Educa, 1997.

. Currículo: Teoria e História. Trad. de Attílio Brunetta. Petrópolis: Vozes, 1998. . O Currículo em mudança. Trad. de Jorge Ávila de Lima. Porto: Porto Editora, 2001.

JULIÁ, Dominique. A Cultura Escolar como Objeto Histórico. Revista Brasileira de História da Educação, Campinas, n.1, p. 9-43, jan./jun., 2001.

. Disciplinas escolares: objetivos, ensino e apropriação. In: MACEDO, Elizabeth; LOPES, Alice Ribeiro Casimiro. Disciplinas e integração curricular: histórias e políticas. Rio de Janeiro: DP\&A editora, 2002. p. 37-71.

KAWAMURA, Maria Regina Dubeux. Disciplina, sim!. Ciência e Ensino, Campinas, n. 2, p. 1-5, jul. 1997.

LEFF, Henrique. Epistemologia Ambiental. São Paulo: Cortez, 2002.

LIMA, Maria Jacqueline Girão Soares de; VASCONCELLOS, Maria das Mercês Navarro. A educação ambiental como disciplina escolar: explicitando a tensão entre teoria e prática. In: ENCONTRO DE PESQUISA EM EDUCAÇÃO AMBIENTAL, IV, 2007, Rio Claro, SP. Anais... Rio Claro, 2007.

LOPES, Alice Ribeiro Casimiro. Conhecimento Escolar em Química - Processo de Mediação Didática da Ciência. Quimica Nova na Escola, São Paulo, v. 20, n. 5, p. 563-568, 1997.

Conhecimento Escolar: Ciência e Cotidiano. Rio de Janeiro: EDUERJ, 1999.

. Relações macro/micro na pesquisa em currículo. Cadernos de Pesquisa, São Paulo, v. 36, n. 129, p. 619-635, set./dez. 2006.

MACEDO, Elizabeth. Parâmetros Curriculares Nacionais: A Falácia de Seus Temas Transversais. In: MOREIRA, Antonio Flavio Barbosa. Currículo: Políticas e Práticas. Campinas: Papirus, 1999. p. 43-58.

MACEDO, Elizabeth; LOPES, Alice Ribeiro Casimiro. A estabilidade do currículo disciplinar: o caso das ciências. In: . (Org.). Disciplinas e Integração Curricular: histórias e políticas. Rio de Janeiro: DP\&A, 2002. p. 73-94. 
NOVICKI, Victor. Abordagens Teórico-Metodológicas na Pesquisa Discente em Educação Ambiental: programas de pós-graduação em educação do rio de janeiro (19812002). In: REUNIÃO ANUAL DA ANPED, 26., 2003, Poços de Caldas. Poços de Caldas: ANPED, 2003.

OLIVEIRA, Cecília S.; FERREIRA, Marcia Serra. Educação Ambiental na Escola: Diálogos com as disciplinas escolares Ciências e Biologia. In: ENCONTRO DE PESQUISA EM EDUCAÇÃO AMBIENTAL, 4., 2007, Rio Claro, SP. Atas eletrônicas... Rio Claro, SP: UNESP, 2007. 1 CD-ROM.

PIERSON, Alice Helena Campos; NEVES, Marcos Rogério. Interdisciplinaridade na formação de professores de ciências: conhecendo obstáculos. Revista Brasileira de Pesquisa em Educação em Ciências, Porto Alegre, v. 1, n. 2, p. 120-131, 2000.

RODRIGUES, Neidson. Educação: da formação humana à construção do sujeito ético. Educação e Sociedade, Campinas, n. 76, p. 232-257, out. 2001.

SILVA, Luciano Fernandes. A Temática Ambiental e o Ensino de Física na Escola Média: a produção de energia elétrica em larga escala como um tema controverso. 2001. 235 f. Dissertação (Mestrado em Educação) - Faculdade de Ciências e Letras, Universidade Estadual Paulista, Araraquara, 2001.

- A Temática Ambiental, o Processo Educativo e os Temas Controversos: implicações teóricas e práticas para o ensino de Física. 2007. 212 f. Tese (Doutorado em Educação) Faculdade de Ciências e Letras, Universidade Estadual Paulista, Araraquara, 2007.

SILVA, Luciano Fernandes; CARVALHO, Luiz Marcelo. O ensino de física e a temática ambiental: a produção de energia elétrica em larga escala como um tema controverso. In: ENCONTRO DE PESQUISA EM ENSINO DE FÍSICA, 10., 2006, Londrina, PR. Atas eletrônicas... Londrina, PR: Sociedade Brasileira de Física, 2006a. 1 CD-ROM.

O Ensino de Física a partir de Temas Controversos: a produção de energia elétrica em larga escala Interações, Santarém-Portugal, v. 1, n. 4, p. 42-63, 2006b. Disponível em: <http://nonio.eses.pt/interaccoes/artigos/D3.pdf>. Acesso em: 27 abr. 2007.

VEIGA-NETO, Alfredo. Tensões disciplinares: recompondo antigos temas. In: SILVA, Aida Maria M. et al. (Org.). Novas subjetividades, currículo, docência e questões pedagógicas na perspectiva da inclusão cultural. Recife: ENDIPE, 2006. p.137-159.

Artigo recebido em 14/11/2007 - Aprovado em 08/06/2008 